\title{
RESENHA
}

\section{Decidir sobre a Carreira Profissional: Um Processo Comportamental}

Choosing a Career: a Behavioral Process

\author{
Elaine Cristina Luiz \\ Olga Mitsue Kubo \\ Universidade Federal de Santa Catarina
}

Gómez, S. G. O. A. (2006). Análise do processo de decidir sobre a carreira profissional de psicólogos docentes universitários. Dissertação de mestrado, Universidade Federal de Santa Catarina, Florianópolis.

"Projetar a vida profissional", "planejar a carreira", "tomar decisões sobre a carreira" são processos já conhecidos por orientadores profissionais. Ainda assim, o conhecimento que está sendo produzido pode contribuir para aumentar a compreensão sobre os processos com os quais os orientadores profissionais lidam. Ao intervir sobre tais processos, fundamentados em conhecimentos de valor de diferentes áreas do conhecimento, em especial em conhecimento psicológico, orientadores profissionais podem auxiliar as pessoas a elaborar projetos de vida coerentes com suas necessidades, interesses e possibilidades e com as necessidades sociais. Contudo, as distinções e relações entre os processos comportamentais de decidir, planejar e projetar a vida profissional ainda necessitam ser mais claramente explicitadas. A dissertação de Gómez (2006), intitulada Análise do processo de decidir sobre a carreira profissional de psicólogos docentes universitários, oferece subsídios para caracterizar com mais precisão os diferentes comportamentos relacionados ao processo de projetar a vida profissional e, por essa razão, merece ser lida.

A clareza da redação da dissertação de Gómez (2006) e a boa estruturação dos parágrafos e capítulos são aspectos que merecem destaque no trabalho. A sequência em que a introdução está organizada auxilia o leitor a entender os questionamentos feitos pela autora como se estivesse dialogando com ela. É dessa forma que a autora apresenta a importância e a necessidade de produzir conhecimento sobre o processo de decidir sobre a carreira. Nas sessões em que apresenta as descrições e análises dos resultados, Gómez (2006) apresenta os subtítulos sob a forma de perguntas e, em seguida, procura respondê-las ao desenvolver o texto.
Em geral, o formato de dissertações não é tão atrativo quanto o de livros, porém a leitura deste trabalho é agradável, justamente pela forma como foi construído.

Para demonstrar a relevância de sua pesquisa e analisar os dados encontrados, a autora utiliza conceitos da Análise do Comportamento, os quais possibilitam compreender que o desenvolvimento da carreira não é independente das ações do profissional. Gómez (2006) demonstra que o processo de decisão não é estático, localizado e pontual, mas que é composto por conjuntos de variáveis que se interligam em um contexto histórico-social determinado. Segundo a autora, a descrição do processo de decidir sobre a carreira possibilita identificar quais são essas variáveis, sendo um bom começo para identificar e descrever os subconjuntos de comportamentos necessários para projetar a vida profissional.

A partir da revisão de literatura, Gómez (2006) questiona qual o tipo e a natureza da relação entre dois comportamentos envolvidos no desenvolvimento da carreira: decidir e perceber. A autora indaga de que forma o comportamento de "perceber as variáveis presentes em cada decisão sobre a carreira" influencia no processo de decidir a carreira profissional. Conclui que "perceber" possibilita aos profissionais construir planos de carreira que levam em consideração as dificuldades e condições facilitadoras no próprio desenvolvimento da carreira. Dessa forma, Gómez identifica um comportamento importante que precisa ser aprendido ou aperfeiçoado por pessoas que estão projetando ou tomando decisões sobre a vida profissional: perceber as variáveis envolvidas em cada decisão.

Os resultados são apresentados em tabelas que apresentam as características dos comportamentos 
identificados a partir dos relatos dos professores. Além disso, Gómez (2006) apresenta, no capítulo 4, uma síntese dos relatos de cada professor entrevistado a respeito das principais decisões tomadas por eles ao longo da carreira. A leitura dessas sínteses possibilita identificar que os relatos dizem respeito ao próprio desenvolvimento das carreiras. Ou seja, as decisões de cada profissional ao longo da carreira constituem um conjunto que pode receber o nome "desenvolver a carreira". Essa constatação é relevante para o profissional que tem a função de orientar os outros a projetar a vida profissional, visto que explicita que cada decisão é especialmente importante e tomar as melhores decisões em dado momento é algo que precisa ser aprendido.

A análise das entrevistas utilizando o conceito de comportamento possibilitou à Gómez (2006) identificar classes gerais de comportamento importantes para estabelecer critérios para decidir, e consequentemente, planejar a própria carreira. Conhecer quais são os comportamentos envolvidos no processo de decidir sobre a carreira pode proporcionar ao orientador profissional uma espécie de guia sobre as aprendizagens importantes e os comportamentos que os "orientandos" precisam apresentar para elaborar projetos profissionais e de vida adequados. É necessário, porém, transformar esse conhecimento em comportamentos de pessoas que projetam sua vida profissional, e essa é uma tarefa para os orientadores profissionais.

A qualidade das descobertas apresentadas pode ser identificada ao longo da apresentação dessas. No entanto, as análises feitas segundo a perspectiva da Análise do Comportamento ainda estão incompletas. Descrever classes de comportamentos e seus componentes nos moldes exigidos por uma análise comportamental implica alguns cuidados que não foram suficientemente atendidos no trabalho. A autora fraciona o relato dos participantes da pesquisa para identificar classes de estímulos antecedentes (situações antecedentes), classes de respostas (ações) e classes de estímulos consequentes (resultados) dos comportamentos. Contudo, a construção apresentada ainda precisaria ser revista e refinada. Classes de estímulos antecedentes se referem a aspectos do ambiente com os quais o sujeito lida e que exercem graus diferenciados de controle sobre uma determinada classe de respostas. Classes de estímulos consequentes se referem a aspectos do ambiente como produto ou decorrência da classe de respostas. Ambas as classes necessitam ser descritas por substantivos para maior precisão e clare- za da função desses dois componentes na caracterização de um comportamento. $\mathrm{Na}$ dissertação, muitas classes de estímulos são descritos por verbos que representam ações que o sujeito faz ou fez, porém, os verbos devem aparecer apenas na descrição das classes de ações. Essa forma de apresentar a análise comportamental pode dificultar ou mesmo comprometer a correta e exata compreensão dos dados que a autora apresenta.

A partir dessa revisão, seria necessário também aperfeiçoar as relações que a autora estabeleceu entre os três componentes do comportamento (classes de estímulos antecedentes, classes de ações e classes de estímulos consequentes). Alguns trechos selecionados como "situações antecedentes" parecem ser insuficientes, ou em alguns casos irrelevantes, na relação com o tipo de classe de respostas indicada e na relação com os "resultados" descritos pela autora. Nos casos em que não foi possível completar as relações entre os três componentes, poderia ter sido feita apenas uma indicação de que alguns dados não foram obtidos a partir das entrevistas. Essas limitações não comprometem a total qualidade do trabalho, mas são aspectos para os quais o leitor necessita estar atento ao ler a dissertação.

Em síntese, Gómez procura caracterizar, de forma clara, objetiva e agradável, as variáveis determinantes do processo de decidir sobre a carreira profissional de psicólogo. Na dissertação é possível encontrar comportamentos importantes que precisam ser aprendidos pelos que estão projetando ou desenvolvendo sua vida profissional e ensinados pelos orientadores profissionais. A leitura permite identificar que decidir e perceber são comportamentos que fazem parte de uma classe de comportamento mais abrangente: desenvolver a carreira. Algumas perguntas surgem a partir dessa leitura: Que outros comportamentos, além dos descritos por Gómez, compõem o processo de desenvolver a carreira? Qual a distinção entre desenvolver a carreira e projetar a vida profissional? Que outros comportamentos são importantes para quem está decidindo sobre, desenvolvendo ou projetando a carreira? Identificar quais são esses comportamentos é fundamental para quem tem a função de "orientar", "ensinar", "facilitar" as decisões ao longo da vida profissional das pessoas. A dissertação de Sandra Gómez, que pode ser encontrada em formato PDF no site da Biblioteca Universitária da UFSC, no link http://www.tede. ufsc.br/teses/PPSI0247.pdf, é um bom começo para estabelecer essas distinções. 


\section{REFERÊNCIAS}

Gómez, S. G. O. A. (2006). Análise do processo de decidir sobre a carreira profissional de psicólogos docentes universitários. Dissertação de mestrado, Universidade Federal de Santa Catarina, Florianópolis. Retirado em 25 de novembro de 2008, de http://www.tede.ufsc.br/teses/PPSI0247.pdf

Recebido: 25/11/2008

Última revisão: 09/04/2009 Aceite final: 30/04/2009

\section{Sobre os autores da resenha:}

Elaine Cristina Luiz: Mestre em Psicologia pela Universidade Federal de Santa Catarina. Endereço eletrônico: elainecluiz@gmail.com.

Olga Mitsue Kubo: Professora Doutora do Departamento de Psicologia e do Programa de Pós-graduação em Psicologia da Universidade Federal de Santa Catarina. Endereço eletrônico: ok@cfh.ufsc.br. 